\title{
Parental Satisfaction and Barriers Affecting Immunization Services in Rural Communities: Evidence from North Ethiopia
}

\author{
Abdu Hussen ${ }^{1}$, Agajie Likie Bogale ${ }^{2, *}$, Jemal Haidar Ali ${ }^{3}$ \\ ${ }^{1}$ Zewditu Memorial Hospital, Addis Ababa City Administration Health Bureau, Addis Ababa, Ethiopia \\ ${ }^{2}$ Ethiopian Public Health Institute, Addis Ababa, Ethiopia \\ ${ }^{3}$ Reproductive Health and Health Service Management, School of Public Health, College of Health Sciences, Addis Ababa University, Addis \\ Ababa, Ethiopia
}

\section{Email address:}

abduhussine@gmail.com (A. Hussen), ephi@ethionet.et (A. L. Bogale), hjemal@gmail.com (J. H. Ali)

${ }^{*}$ Corresponding author

\section{To cite this article:}

Abdu Hussen, Agajie Likie Bogale, Jemal Haidar Ali. Parental Satisfaction and Barriers Affecting Immunization Services in Rural Communities: Evidence from North Ethiopia. Science Journal of Public Health. Vol. 4, No. 5, 2016, pp. 408-414. doi: 10.11648/j.sjph.20160405.17

Received: July 21, 2016; Accepted: August 2, 2016; Published: August 29, 2016

\begin{abstract}
The purpose of this study was to examine barriers affecting client satisfaction with immunization services rendered in rural district, Ethiopia. A total of 419 caretakers who accessed the service were included and assessed for their satisfaction level using a pretested questionnaire that contained socioeconomic, demographic information, knowledge and various items related to process, service and accessibility factors on immunization service. The response rate was $99.3 \%$ and nearly two third of caretakers were satisfied with childhood immunization service. The majorities of caretakers were mothers and over three quarters had formal education. The highest mean rating score of 2.03 was observed in vaccine availability. The major determinants were related to low knowledge on vaccine preventable child illness; desire to vaccinate breastfeeding child and quality of care score. To maximize the benefits of vaccine preventable illnesses and improve the satisfaction levels, augmenting the knowledge of caretakers on vaccine preventable child illnesses and improving the quality of the service is crucial.
\end{abstract}

Keywords: Caretaker Satisfaction, Vaccine Preventable Child Illness, Quality, Rural Ethiopia

\section{Background}

Childhood immunization is considered to be among the most effective preventive services and is one of the most important public health interventions which is cost effective to reduce both morbidity and mortality associated with infectious diseases [1]. In 2003 alone, it is estimated that immunization averted more than 2 million deaths globally suggesting that immunization is among the most effective preventive services, and is therefore critical to monitor and evaluate the service from provider as well as consumers end [2] satisfaction. Parental satisfaction is the most important element when dealing with pediatric care because their role is pivotal and it is considered an indicator of provider quality that has been relatively unexplored in relation to childhood immunization [3, 4]. Moreover, Satisfaction has been said to be a major predictor of use of services, as it is essential if clients were to utilize services, comply with treatments and maintain a continuing relationship with practitioners [5].

The regional immunization strategic plan 2009-2013 including Ethiopia provided significant thrust for immunization coverage depicted mainly in DiphtheriaTetanus-Pertussis (DTP3). Measles mortality has declined by $88 \%$ since 2000 . The development of a new vaccine against meningococcal meningitis type $\mathrm{A}$ and its introduction has protected millions of children and young adults living in meningitis belt of sub-Saharan Africa from the eruption of the disease [6].

In Ethiopia though the expanded program of immunization 
was launched in 1980, the coverage in the first twenty years was very low due to factors related to lack of providing appropriate information on vaccines, poor training facilities of health workers and inaccuracies in the registration of vaccinations [7].Others documented knowledge related to age specific vaccinations as an impediment to the low uptake of the service $[8,9]$. Very recently, in addition to knowledge related to age specific childhood vaccination, courtesy of health extension workers and distance to reach the facilities are among other important determinants affecting the service [10]. Despite all these barriers encountered, the country has performed well in routine immunization coverage as of 2003 [11] though more is projected implying some more uncovered barriers are prevailing which need to be studied.

While many studies attempted to evaluate performance of immunization through coverage, there is scarce or limited evidences or nil particularly in the proposed study sites suggesting a growing awareness about the limitations of such evaluation, in terms of parental satisfaction and barriers affecting the services which this study has uncovered and availed some more evidence based information for some more initiatives in the community as well as in the country.

\section{Methods}

\subsection{Study Area and Population}

A health facility based cross sectional study was conducted in Kombolcha town, South wollo zone of Amhara national regional state-Ethiopia from March to April 2015. It is located $375 \mathrm{~km}$ from Addis Ababa and home for 126,145 populations. The district has 12 kebeles and four health centers. All the four health centers with static immunization services available in the area were included. The name of the health centers and the population they served at the time of the study were $02 \mathrm{HC}(\mathrm{N}=33,571), 03 \mathrm{HC}(\mathrm{N}=56,289), 05 \mathrm{HC}$ $(\mathrm{N}=26,059)$ and $07 \mathrm{HC}(\mathrm{N}=10,226)$, respectively.

The physical health service coverage of the zone is $42.2 \%$ [12] with very scanty information on immunization related services. Because of the aforementioned reasons, the site was deliberately selected to examine the status quo of childhood immunization service and the level of satisfaction among parents who accessed the service.

\subsection{Ethical Considerations}

Ethical clearance was obtained from the school of Public Health Research and Ethical Committee (REC), College of Health Sciences, Addis Ababa University. An official letter was also written from the school of Public Health to Kombolcha city administration health office to get permission and cascade the information to the respective health center. Informed written consent was obtained from all participants for their participation after the nature of the study was fully explained to them in their local languages. All the information obtained from the participants is kept confidential and identification of each participant is only possible through numerical codes.

\subsection{Sample Size Determination, Data Entry, Processing and Analysis}

The required sample size was determined using single population proportion formula assuming a proportion of $50 \%$ (since no data are available), level of significance of 0.05 with marginal error of $5.0 \%$ and a non-response rate of $10.0 \%$ yielding a sample size of 422 . The estimated sample size was allocated to the available health centers namely $02 \mathrm{HC}(\eta=93), 03 \mathrm{HC}(\eta=144), 05 \mathrm{HC}(\eta=125)$ and $07 \mathrm{HC}(\eta$ $=60$ ), respectively based on served client proportion to size.

A pre-tested questionnaire prepared in English and later translated to the local language was used after pretesting it in ten percent of the estimated sample size to cross check the reliability or consistency of data collection tools in similar settings among non-sampled caretakers close to the district. The pretested questionnaire was used to collect caretakers' information on socioeconomic characteristics, knowledge, and various satisfactory items that included process, service and accessibility factors on childhood immunization service through face to face interview.

Prior to the study, a two-day intensive training on the objective and data collection techniques was given to four recruited experienced nurses fluent in the local language drawn from the district at central level by the principal investigator. To maintain data quality, each collected data were checked for completeness and consistency daily by principal investigator. The collected data were coded and entered using Epi-Info 3.5.3 and analyzed in SPSS version 21. The results are presented in percentages and graph. The mean Likert scale score was used to categorize satisfaction level as satisfied when the score is greater than the cutoff value while the value below the cutoff is considered as dissatisfied. The mean rating score for each item was calculated by multiplying the number of responses in each category using its rating which ranged from value zero for poor to three for excellent, 2 for good and 1 for fair responses-all values were added up and divided by the total number of responses for the specified item to provide greater variability and less skewness of responses. To convert the score into percentage for meaningful presentation, we multiplied each item frequency by 100 and divided by 3 (excellent rate) as suggested by Alla [13].

Binary logistic regression was used to examine the association between the outcome variable and predictors, and the results are presented using odds ratios (ORs) and confidence interval $(95 \% \mathrm{CI})$. To find out the association between the dependent variable and the explanatory variables, stepwise logistic regression was applied and adjusted odds ratio (AOR) with confidence interval (95\% CI) was constructed to rule out the confounders. In all analysis, $\mathrm{p}<0.05$ was considered as statistically significant.

\section{Results}

A total of 419 respondents participated making the response rate $99.3 \%$ (419/422). Less than half (42.7\%) aged 
between 25-30 years. The majority of caretakers were mothers $(95.9 \%)$ and in marital union $(89.7 \%)$. Over threefourth $(81.1 \%)$ had formal education and three fourth
$(75.7 \%)$ of respondents were homemakers. Slightly over half $(51.6 \%)$ of caretakers took their children for age specific vaccination service (Table 1).

Table 1. Socio-demographic characteristics of caretakers, Konbolcha, north Ethiopia, 2015 (n=419).

\begin{tabular}{lll}
\hline Variables & Frequency & Percent \\
\hline Age (in years ) & 12 & 2.9 \\
$15-19$ & 151 & 36.0 \\
$20-24$ & 179 & 42.7 \\
$25-30$ & 77 & 18.4 \\
$>30$ & 402 & \\
Relation of caretakers to child & 17 & 95.9 \\
Mothers & & 4.1 \\
Fathers & 376 & \\
Marital status & 43 & 89.7 \\
Married & & 10.3 \\
Unmarried & 79 & 18.9 \\
Educational status & 192 & 45.8 \\
Uneducated & 148 & 35.3 \\
Intermediate & & \\
Tertiary & 102 & 24.3 \\
Employment status & 317 & 75.7 \\
Yes (employee) & & \\
No (homemakers) & 216 & 51.6 \\
Took children for age specific vaccination & 203 & 48.4 \\
Yes & & \\
No & & \\
\hline
\end{tabular}

Table 2 displays the important variables or items addressed in the study. Based on the knowledge items assessed, the majority $(85.7 \%)$ were aware about EPI targeted diseases and the importance of EPI in preventing common childhood illnesses (95.2\%). The majority agreed to vaccinate breastfeeding child $(95.5 \%)$, and supported the completion of the full dose $(90.9 \%)$ and adhered with the vaccination schedule $(91.6 \%)$ with an overall knowledge score of $62.3 \%$.

According to the process factors, the majority were happy with the cleanliness of the waiting room $(85.7 \%)$ and when the child received the vaccination $(85.4 \%)$. Over one third was greeted by service providers $(36.3 \%)$ and did not complain with the vaccinating waiting time (35.1\%) and received information about the common child vaccines (33.2) and the doses received (10.3).

In terms of access factors assessed, the majority visited the vaccination center to get the service $(97.4 \%)$, and had a visit of 1-4 times $(88.5 \%)$. The time taken to reach the center was between 30-60 minutes in 173 (39.6\%). Two-thirds (66.0\%) of them stated the service waiting time to take $15-30$ minutes and $224(53.5 \%)$ mentioned that the time taken for injecting the vaccine was less than 10 minutes.

Table 2. Knowledge, process and service accessibility factors on childhood Konbolcha, north Ethiopia, 2015 (n=419).

\begin{tabular}{|c|c|c|c|}
\hline \multirow{2}{*}{ Items Assessed } & \multirow{2}{*}{ Levels } & \multicolumn{2}{|c|}{ Respondents category } \\
\hline & & Yes Freq (\%) & No Freq (\%) \\
\hline \multirow{7}{*}{ Knowledge } & Aware EPI target diseases & $359(85.7)$ & $60(14.3)$ \\
\hline & Aware that EPI prevents childhood illnesses & $399(95.2)$ & $20(4.8)$ \\
\hline & Agreed to vaccinate breastfeeding child & $400(95.5)$ & $19(4.5)$ \\
\hline & Agreed to complete full dose vaccination & $381(90.9)$ & $38(9.1)$ \\
\hline & Adhered with the vaccination schedule & $384(91.6)$ & $35(8.4)$ \\
\hline & Over all knowledge score & $261(62.3)$ & $158(37.7)$ \\
\hline & Was happy with the waiting room cleanliness & $359(85.7)$ & $60(14.3)$ \\
\hline \multirow{7}{*}{ Process } & Was happy when child vaccinated & $358(85.4)$ & $61(14.6)$ \\
\hline & Greeted by service provider & $152(36.3)$ & $267(63.7)$ \\
\hline & Did not complain with the vaccinating waiting time & $147(35.1)$ & $272(64.9)$ \\
\hline & Received information about EPI & $139(33.2)$ & $280(66.8)$ \\
\hline & informed about common childhood vaccine types & $149(35.6)$ & $270(64.4)$ \\
\hline & Briefed onthe dose of vaccine administered & $43(10.3)$ & $376(89.7)$ \\
\hline & Over all process score & $256(61.1)$ & $163(38.9)$ \\
\hline \multicolumn{4}{|l|}{ Access } \\
\hline \multirow{2}{*}{ Cause for visit } & To vaccinate the child & 408 & 97.4 \\
\hline & Appointment/Follow-up & 11 & 2.6 \\
\hline \multirow{2}{*}{ Visit frequency } & $1-4$ times & 371 & 88.5 \\
\hline & $\geq 5$ times & 48 & 11.5 \\
\hline \multirow{3}{*}{$\begin{array}{l}\text { Time reached toservice } \\
\text { center }\end{array}$} & $<30 \min$ & 173 & 41.3 \\
\hline & $30-60 \mathrm{~min}$ & 166 & 39.6 \\
\hline & $>60 \mathrm{~min}$ & 80 & 19.1 \\
\hline
\end{tabular}




\begin{tabular}{llll}
\hline \multirow{2}{*}{ Items Assessed } & Levels & Respondents category & No Freq (\%) \\
\cline { 3 - 4 } Service Waiting time & $<15 \mathrm{~min}$ & Yes Freq (\%) & 10.0 \\
& $15-30 \mathrm{~min}$ & 279 & 66.6 \\
\multirow{2}{*}{ Time taken for injecting } & $>30 \mathrm{~min}$ & 98 & 23.4 \\
the vaccine & $5-10 \mathrm{~min}$ & 76 & 18.1 \\
& $>10 \mathrm{~min}$ & 224 & 53.5 \\
\hline
\end{tabular}

Note: freq=frequency of responded items, $\%=$ percentage of responses

Table 3 shows the mean rating and percent of mean score for each item of aspects of care. As shown, the highest mean rating score was seen for vaccine availability and vaccine effectiveness. The mean rating and percent for vaccine availability was 2.03 and $67.7 \%$ score while for vaccine effectiveness the mean rating and percent was 2.00 and
$66.7 \%$.The lowest mean rating score was observed in cleanness of waiting area and cleanness of examination rooms. The mean rating and percent for cleanness of waiting area was 1.52 and $50.7 \%$ while for cleanness of examination rooms it was 1.59 and $53.0 \%$.

Table 3. Mean rating score for items of health care in Konbolcha town, Amhara Regional State,north Ethiopia, 2015 ( $n=419)$.

\begin{tabular}{|c|c|c|c|c|c|c|}
\hline Aspects of care & $\begin{array}{l}\text { Poor Freq } \\
(\%)\end{array}$ & $\begin{array}{l}\text { Fair Freq } \\
(\%)\end{array}$ & $\begin{array}{l}\text { Good Freq } \\
(\%)\end{array}$ & $\begin{array}{l}\text { Excellent } \\
\text { Freq (\%) }\end{array}$ & $\begin{array}{l}\text { Mean } \\
\text { rating score }\end{array}$ & $\begin{array}{l}\text { Percent of } \\
\text { mean score }\end{array}$ \\
\hline Effectiveness of care & 0 & $84(20)$ & $335(80)$ & 0 & 1.80 & 60.0 \\
\hline Kindness of registers & 0 & $94(22.4)$ & $325(77.6)$ & 0 & 1.78 & 59.3 \\
\hline Attitude of service providers towards clients & 0 & $89(21.2)$ & $327(78.1)$ & $3(0.7)$ & 1.79 & 59.7 \\
\hline Building and infrastructure & $5(1.2)$ & $61(14.6)$ & $341(81.4)$ & $12(2.9)$ & 1.86 & 62.0 \\
\hline Tools and equipments & $5(1.2)$ & $71(16.9)$ & $326(77.8)$ & $17(4.1)$ & 1.85 & 61.7 \\
\hline Performance of service providers & $13(3.1)$ & $92(22.0)$ & $314(74.9)$ & 0 & 1.72 & 57.3 \\
\hline Sanitation or hygiene of clinic & $3(0.7)$ & $72(17.2)$ & $344(82.1)$ & 0 & 1.81 & 60.3 \\
\hline Availability of vaccine & 0 & $7(1.7)$ & $393(93.8)$ & $19(4.5)$ & 2.03 & 67.7 \\
\hline Providers information about vaccine side effect/illness & $18(4.3)$ & $128(30.5)$ & $264(63.0)$ & $9(2.1)$ & 1.63 & 54.3 \\
\hline Information and documentation & $8(1.9)$ & $69(16.5)$ & $342(81.6)$ & 0 & 1.80 & 60.0 \\
\hline Vaccine effectiveness & 0 & $21(5.0)$ & $382(91.2)$ & $16(3.8)$ & 2.00 & 66.7 \\
\hline Cleanness of waiting area & $41(9.8)$ & $153(36.5)$ & $192(45.8)$ & $33(7.9)$ & 1.52 & 50.7 \\
\hline Cleanness of examination room & $8(1.9)$ & $155(37.0)$ & $256(61.1)$ & 0 & 1.59 & 53.0 \\
\hline
\end{tabular}

Note: freq=frequency of responded items, $\%=$ percentage of responses

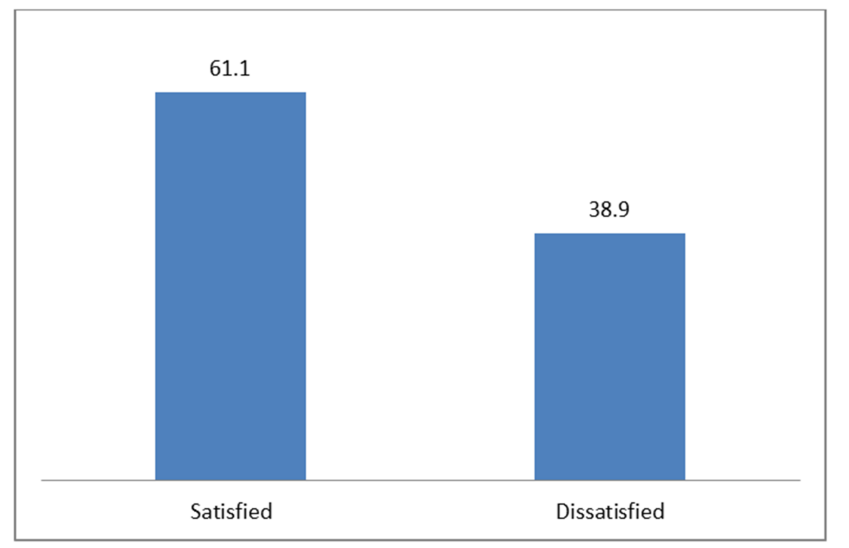

Figure 1. Satisfaction score for childhood immunization delivered in Konbolchatown, north-Ethiopia.

Figure 1 demonstrates the overall satisfaction score of the respondents. As shown about two-thirds $(61.1 \%)$ of them were satisfied with childhood immunization services delivered in the entire health centers. This satisfaction score is calculated using Likert scale of measurement from items of satisfaction like cleanness of waiting room, happiness when child vaccinated, greeting by service provider, so forth and the values higher through the cut off $(\geq 10)$ or the mean average is considered as satisfied.

Table 4 depicts the determinants of respondent's satisfaction with childhood immunization services. The major determinants identified for respondent's satisfaction were knowledge about immunization preventable illness, desire to vaccinate breastfeeding child and quality of care score $(p<0.05)$. Respondent's who had no knowledge about immunization preventable illness were $80.0 \%$ less likely satisfied than the referent groups (AOR $=0.20,95 \% \mathrm{CI}=0.05$ 0.89 ), and the odds to be satisfied with the service was more than 19 times among respondents who had the desire to vaccinate their breastfeeding child(AOR $=19.15, \quad 95 \%$ $\mathrm{CI}=2.46-148.97$ ) than those who did not. Respondents that had perceived the quality of care score as low were 2 times more likely to be satisfied than their counterparts ( $\mathrm{AOR}=2.11,95 \% \mathrm{CI}=1.36-3.28)$. Nonetheless, all the sociodemographic and other independent variables considered in the study didn't show significant association with the 
satisfaction level of respondents $(\mathrm{p}>0.05)$.

Table 4. Univariate and multivariate analysis for predictors of child hood immunization satisfaction in Konbolchatown, north-Ethiopia, 2015 ( $n=419)$.

\begin{tabular}{|c|c|c|c|c|}
\hline Variables & Satisfied ( $\geq 10.8)$ Freq (\%) & Dissatisfied (<10.8) Freq (\%) & COR $(95 \% \mathrm{CI})$ & AOR (95\% CI) \\
\hline \multicolumn{5}{|c|}{ Parental age in years } \\
\hline $15-19$ & $7(58.3)$ & $5(41.7)$ & 1 & \\
\hline $20-24$ & $98(64.9)$ & $53(35.1)$ & $1.32(0.40-4.37)$ & \multirow[t]{3}{*}{ - } \\
\hline $25-30$ & $109(60.9)$ & $70(39.1)$ & $1.11(0.34-3.64)$ & \\
\hline$>=31$ & $42(54.5)$ & $35(45.5)$ & $0.86(0.25-2.94)$ & \\
\hline \multicolumn{5}{|l|}{ Parental sex } \\
\hline Female & $244(60.7)$ & $158(39.3)$ & 1 & \multirow[t]{2}{*}{-} \\
\hline Male & $12(70.6)$ & $5(29.4)$ & $1.55(0.54-4.49)$ & \\
\hline \multicolumn{5}{|l|}{ Marital status } \\
\hline Married & $228(60.6)$ & $148(39.4)$ & 1 & \multirow[t]{3}{*}{-} \\
\hline Unmarried & $28(65.1)$ & $15(34.9)$ & $1.21(0.63-2.35)$ & \\
\hline \multicolumn{4}{|l|}{ Employment } & \\
\hline Employee & $65(63.7)$ & $37(36.3)$ & 1 & \multirow[t]{2}{*}{-} \\
\hline Homemakers & $191(60.3)$ & $126(39.7)$ & $0.86(0.54-1.37)$ & \\
\hline \multicolumn{5}{|c|}{ Know common child hood illnesses can be prevented by immunization } \\
\hline Yes & $238(59.6)$ & $161(40.4)$ & 1 & 1 \\
\hline No & $18(90.0)$ & $2(10.0)$ & $0.16(0.04-0.72)$ & $0.20(0.05-0.89)^{*}$ \\
\hline \multicolumn{5}{|c|}{ Need to vaccinate breastfeeding child } \\
\hline Yes & $238(59.5)$ & $162(40.5)$ & 1 & 1 \\
\hline No & 18 (94.7) & $1(5.3)$ & $12.25(1.62-92.69)$ & $19.2(2.5-148.97)^{*}$ \\
\hline \multicolumn{5}{|c|}{ Time spent for injecting the vaccine } \\
\hline$<5 \min$ & $52(68.4)$ & $24(31.6)$ & 1 & 1 \\
\hline $5-10 \mathrm{~min}$ & $140(62.5)$ & $84(37.5)$ & $0.77(0.44-1.34)$ & $0.77(0.43-1.35)$ \\
\hline$>10 \mathrm{~min}$ & $64(53.8)$ & $55(46.2)$ & $0.54(0.29-0.98)$ & $0.55(0.29-1.03)$ \\
\hline \multicolumn{5}{|c|}{ Quality of care score } \\
\hline High & $187(66.1)$ & $96(33.9)$ & 1 & 1 \\
\hline Low & $69(50.7)$ & $67(49.3)$ & $0.53(0.35-0.80)$ & $2.11(1.36-3.28)^{*}$ \\
\hline
\end{tabular}

*showed significant association, freq=frequency of items, $\%=$ percentage, cutoff value $=10.8$

\section{Discussion}

Universal childhood immunization introduced through EPI is the most efficient public health innovation for the prevention of vaccine-preventable common child illnesses provided that the program is uninterrupted and parents are satisfied with the service and adhere to the program. Although there are new vaccination initiatives globally, the discussions are limited to the common types of vaccinations used in Ethiopia among respondents who had taken their children to the health facilities.

Based on the knowledge items assessed in this study, the results are encouraging since the majority of caretakers were aware about EPI targeted diseases including the importance of vaccine preventable childhood illnesses with an overall satisfaction rate of $61.1 \%$. Compared with the study done among pastoralists communities in Ethiopia, which focused on quality aspect of the EPI program, the satisfaction level observed in the present study is relatively better $(61.1 \%$ vs. $53.3 \%$ ) [14]. This is expected since in the present study the populations assessed are permanent settler as opposed to the pastoralists' study whose study participant probability of skipping the services is high because they travel in search of water and pasture.

Nevertheless, when compared with the Egypt study (61.1\% vs. 95.2\%), Nigeria (61.1\% vs. $89.7 \%$ ), Lucknow India (61.1\%vs. 90\%), and Timor $(61.1 \%$ vs. $97.0 \%)$ findings, the present figure is low because of the difference in vaccine set up and work ethics. For instance, in Egypt [3], the vaccination set up was entirely different from ours and inNigeria due to the difference in the method of vaccination and the set up [15] while in India better reception of clients [16] and in Timor good information delivery system were cited as important factors [17].

When the knowledge score is further aggregated and compared with the Nigerian $\operatorname{study}(62.3 \%$ vs. $87 \%)$, sill it is lower and EPI coordinators need to do more advocacy work that includes better reception, coherent information and proper work ethics during the service delivery [18]. This high level of knowledge observed may be attributable to the quality of information provided to mothers at the health facilities.

In terms of the process factors, the majorities were happy with the cleanliness of the waiting room and when the child received the vaccination though there was dissatisfaction with the vaccinating waiting time and in vaccine related information delivery during the service and is concordant with the study done among the pastoralists community in east Ethiopia [14].

In this study, the highest mean rating score was for vaccine availability and vaccine effectiveness whereas the lowest mean rating score was for cleanness of waiting area and cleanness of examination rooms and similar findings were recognized in the Bangladesh study [19] which acknowledged that cleanness of waiting area and examination room, and even low quality of care to enhance dissatisfaction of participants and it is felt a gray area that needs some improvement.

The major determinants identified for caretakers' 
satisfaction were knowledge about vaccine preventable childhood illness; desire to vaccinate breastfeeding child and quality of care score. Caretakers' who had knowledge about childhood immunization were more satisfied in the service delivered than those with low knowledge about immunization preventable illness. The odds to be satisfied with the service were significantly higher among those who had the desire to vaccinate their breastfeeding child and had perceived high quality of care service delivered in the health facilities on cleanness of waiting area and examination room, accessibility of vaccine and vaccine effectiveness, provider performance and courtesy of service providers with clients.

Surprisingly none of the socio-demographic and other independent variables considered in the study showed significant association with the satisfaction level of respondents and the findings concur with the Bangladeshistudy where age-group and education had no association with satisfaction. Contrary to our present findings, the study done among pastoralis community documented that age, time spent to reach health facility, and waiting time to get the service were important predictors of maternal satisfaction with the immunization service provided [14] deserving further study.

\section{Strength and Limitations}

The high response rate and identifying the important barriers of caretaker satisfaction for some programmatic initiatives could be considered as the strength of this study. Identification of temporal relationship, social desirability biases are acknowledged as limitation of the study. In addition, the available little researches in the area were limited in statistical capacity and we found all previous studies unsuitable for comparison because they reported only frequency percentage for satisfaction items as opposed to our study in which we used average score for the interpretation of satisfaction and minimized biases.

\section{Conclusion}

Although several studies attempted to evaluate performance of immunization based on coverage the gaps in terms of caretaker's satisfaction and barriers affecting the services had not been dealt well in the Ethiopian context. This study has examined and identified the important barriers affecting both caretakers' satisfaction and service delivery which ranged from knowledge about vaccine preventable childhood illness; desire to vaccinate breastfeeding child and quality of care score. To maximize the benefits of vaccine preventable illnesses and improve the satisfaction levels, augmenting the knowledge of caretakers on vaccine preventable child illnesses and improving the quality of the service is crucial.

\section{Authors' Contributions}

AH collected data, thesis write-up and presented the finding. AL contributed for thesis review, data analysis and manuscript preparation. JH designed the study, participated from the inception of the study up-to finalization of the thesis work. All authors read, critically revised and approved the final manuscript.

\section{Acknowledgement}

From the outset this study would have not reached its present stage had been not to the tremendous level of effort levied by the senior author Dr. JemalHaidar. We express our gratitude to the respective health facilities of the regions, the study participants, data collectors, and supervisors for their unreserved support. This study was funded by the Addis Ababa School of Public Health.

\section{References}

[1] World Health Organization (WHO) Department of immunization, vaccines and biological $\mathrm{CH}-1211$, Geneva 27, Switzerland; Global Immunization Vision and Strategy. 20062015.

[2] World Health Organization (WHO). Global eradication of poliomyelitis by the year 2000, World Health Assembly, Resolution no. 41. 28. Geneva: 1988.

[3] Rahman HAA. Maternal satisfaction about childhood immunization in primary health care center, Egypt, Peer J Pre Prints 2013; 1: 171.

[4] Schempf AH, Minkovitz CS, Strobino DM, Guyer B. Parental Satisfaction with Early Pediatric Care and Immunization of Young Children: The Mediating Role of Age-Appropriate Well-Child Care Utilization, Arch Pediatr Adolesc Med 2007; 161: 50-6.

[5] Ministry of Health. Final Report: Client Satisfaction with Health Services in Uganda, 2008.

[6] World Health Organization (WHO). Regional Strategic Plan for Immunization, 2014-2020.

[7] Federal Ministry of Health (FMOH). Ethiopia National Expanded program on Immunization, Comprehensive Multiyear plan 2011-2015; Addis Ababa- December, 2010.

[8] Etana B, Deressa W. Factors associated with complete immunization coverage in children aged 12-23 months in Ambo Woreda, Central Ethiopia, BMC Public Health 2012; 12: 566.

[9] Kassahun MB, Biks GA, Teferra AS. Level of immunization coverage and associated factors among children aged 12-23 months in Lay Armachiho District,North Gondar Zone, North west Ethiopia, BMC Res Notes 2015; 8: 239.

[10] Legesse E, Dechasa W. Assessment of child immunization coverage and its determinants in Sinana Distric, South east Ethiopia, BMC Pediatrics 2015; 15: 31

[11] Kidane T, Yigzaw A, Sahilemariam Y, Bulto T, Mengistu H, Belay $\mathrm{T}$, et al. National EPI coverage survey report in Ethiopia, 2006.

[12] South Wollo Zonal Health Office. Health care of women and children in developing countries, mid-year activity report, phc. 1990. 19: 80-4. 
[13] Allah ESA, Elsabagh EEM, Awady SEI. Mother's Satisfaction with the Quality of Care of Maternal \& Child Health Services at Maternal and Child Health Centers in Zagazig City, Sharika Governorate, Egypt. Life Sci J 2012; 9 (3): 1438-48.

[14] Salah AA, Baraki N, Egata G, Godana W. Evaluation of the Quality of Expanded Program on Immunization Service Delivery in Primary Health Care Institutions of Jigjiga Zone Somali Region, Eastern Ethiopia, European Journal of Preventive Medicine 2015; 3 (4): 117-23.

[15] Emelumadu OF, Onyeonoro UU, Ukegbu AU, Ezeama NN, Ifeadike $\mathrm{CO}$, Okezie OK. Perception of quality of maternal healthcare services among women utilizing antenatal services in selected primary health facilities in Anambra State, Southeast Nigeria, Niger Med J 2014; 55 (2): 148-55.

[16] Nath B, Singah JV, Awasthi S, Bhushan V, Singh SK, Kumar
V. Client Satisfaction with Immunization Services in Urban Slums of Lucknow District, Indian. J Pediatr 2009; 76 (5): 479-83.

[17] Amin R, de Oliveira TJCR, Cunha MD, Brown TW, Favin M, Cappeliera K. Factors limiting immunization coverage in urban Dili, Timor-Leste. Glob Health SciPract. 2013; 1 (3): 417-27.

[18] Odusanya OO, Alufohai EF, Meurice FP, Ahonkhai VI. Determinants of vaccination coverage in rural Nigeria. BMC Public Health 2008; 8: 381.

[19] Hasan A. Patient satisfaction with maternal and child health services among mothers attending the maternal and child health training institute in Dhaka, Bangladesh; Mahidol University 2007. 